\title{
Correction
}

\section{Correction: Kang, K.A.; et al., Myricetin Protects Cells against Oxidative Stress-Induced Apoptosis via Regulation of PI3K/Akt and MAPK Signaling Pathways. Int. J. Mol. Sci. 2010, 11, 4348-4360}

\author{
Kyoung Ah Kang ', Zhi Hong Wang ', Rui Zhang ', Mei Jing Piao ${ }^{1}$, Ki Cheon Kim ${ }^{1}$, \\ Sam Sik Kang ${ }^{2}$, Young Woo Kim ${ }^{3}$, Jongsung Lee ${ }^{3}$, Deokhoon Park ${ }^{3}$ and Jin Won Hyun ${ }^{1, *}$ \\ 1 School of Medicine and Applied Radiological Science Research Institute, Jeju National University, \\ Jeju 690-756, Korea; E-Mails: legna48@hanmail.net (K.A.K.); wzh407@hotmail.com (Z.H.W.); \\ zhangrui26@hotmail.com (R.Z.); mjpiao@hanmail.net (M.J.P.); svv771@hanmail.net (K.C.K.) \\ 2 College of Pharmacy, Seoul National University, Seoul 110-460, Korea; \\ E-Mail: sskang@snu.ac.kr \\ 3 Biospectrum Life Science Institute, Gunpo 435-833, Korea; \\ E-Mails: ywkim@biospectrum.com (Y.W.K.); jslee@biospectrum.com (J.L.); \\ pdh@biospectrum.com (D.P.) \\ * Author to whom correspondence should be addressed; E-Mail: jinwonh@jejunu.ac.kr; \\ Tel.: +82-64-754-3838; Fax: +82-64-702-2687.
}

Received: 3 December 2014 / Accepted: 5 December 2014 / Published: 8 January 2015

The authors want to change Figure 1 of the paper published in IJMS [1]. In Figure 1, 5-position of $\mathrm{OH}$ was at 6-position. Therefore, Figure 1 is revised as follows. The authors would like to apologize for any inconvenience caused to the readers by this change.<smiles>O=c1c(O)c(-c2cc(O)c(O)c(O)c2)oc2cc(O)cc(O)c12</smiles>

Figure 1. Chemical structure of myricetin $\left(3,3^{\prime}, 4^{\prime}, 5,5^{\prime}, 7\right.$-hexahydroxyflavone). 


\section{Reference}

1. Kang, K.A.; Wang, Z.H.; Zhang, R.; Piao, M.J.; Kim, K.C.; Kang, S.S.; Kim, Y.W.; Lee, J.; Park, D.; Hyun, J.W. Myricetin protects cells against oxidative stress-induced apoptosis via regulation of PI3K/Akt and MAPK signaling pathways. Int. J. Mol. Sci. 2010, 11, 4348-4360.

(C) 2015 by the authors; licensee MDPI, Basel, Switzerland. This article is an open access article distributed under the terms and conditions of the Creative Commons Attribution license (http://creativecommons.org/licenses/by/4.0/). 